\title{
Discussion on the Application of 3D Printing Technology in Die Manufacturing
}

\author{
Tianyu Liang
}

\author{
Dalian Vocational \& Technical College, Liaoning Dalian, 116035
}

Key words: 3D printing technology; mold manufacturing; application discussion

\begin{abstract}
With the development of the times and social progress, 3D printing technology of our country gradually began to rise, is a kind of rapid prototyping technology in the present stage of our country, has gradually entered people's life, aroused people's interest and attention, and has been in a number of areas for the use of. The important point is that the current mold manufacturing industry is the basis of our national industry, mold manufacturing industry has become an important industry in the national economy of our country, has a very good position. 3D printing technology in the mold manufacturing industry in the application of the degree of deepening and expanding, has become a strong momentum in the future development of our country. The author first analyzes the working principle of 3D printing technology, development advantages and the characteristics of mold industry in the future, and the use of 3D printing technology mold related examples to analyze the specific manufacturing, finally puts forward the existing 3D printing technology problems and future development direction.
\end{abstract}

\section{Preface}

At this stage, most of our country's products are dependent on the manufacture of mold printing technology, and in the process of industrial production, $60 \%$ to $90 \%$ of the industrial products need mold processing. With the mold for the processing and manufacturing of products, greatly improved the efficiency of industrial products, and for the final product production and renovation to create a good condition. At present, due to the dependence of the industrial products on the mold, and its mold manufacturing has some limitations, the development of all molds is particularly important. The development of the mold has technical difficulties, and the appearance of the different parts of the mold will also affect the extent of the mold. In general, the more complex the results of the parts, then the more difficult to mold manufacturing. So, can the influence factors of future product development has many aspects, including mold design level, industrial enterprises in manufacturing power, the quality of the mold manufacturing, mold manufacturing and processing equipment quality etc.. Only the effective reduction of the number of mold production, can reduce the cost of the product. 3D printing technology effectively complements the shortcomings of the traditional manufacturing methods, so that the mold manufacturing reform technology has made certain progress[1].

\section{D printing technology work principle and characteristic}

3D printing technology has a special advantage, in the application of 3D printing technology for mold production, no longer the basic situation of the mold into account, especially in the production tool surface is particularly easy to operate. With the development of science and technology, the original material under normal conditions and the properties of materials are able to constantly improve and perfect and supplement, and also can adapt to the traditional manufacturing method, it has a very important significance in the mold industry.

The pace of development of 3D printing technology at this stage very quickly, according to the degree of development can know the common 3D printing technology and traditional printer working principle is similar, only the material used is the ink printer, and printer using 3D from the manufacturing process is wax and adhesive resin and other materials. These materials are of great help to the mold making of 3D printing technology. At present, there are mainly three kinds of 3D 
printing technology: fused deposition, rapid prototyping, 3D powder bonding and stereolithography. Fused deposition rapid prototyping, mainly refers to the melt material of some filamentous melts, and effectively to melt the material after ejection, and then on the deposition of cured materials before the treatment, according to this step, the accumulation of material in layers, to achieve the ultimate goal of products effective. Fused deposition is the most widely used technique in our 3D printing technology at this stage. Its manufacturing cost is low and the operation mode is easy to master. The main work is the method of 3D powder bonded to the laying of some of the material in the original plane, and then through some adhesive bonding, waiting for the final molding, it will form an industrial model, the formation of 3D printing products wanted. Light curing the main working principle is using the light curing material is irradiated by the light source or laser heat sensitive materials, can be cured through a layer after irradiation, and obtain the final product. The development of this technology at this stage is also very mature, and it can be used to print the components with more complicated structure and higher precision[2].

With the development of the times, the application of 3D printing technology is gradually being welcomed, and has become one of the main methods to promote industrial upgrading in the industrial industry. 3D printing technology at this stage has three important features: product production cycle is short, complex products in the molding speed of the model, the product manufacturing accuracy is higher. 3D printing technology has a very good advantage, to a certain extent, effectively shorten the production cycle, and can simplify the production process, further omit the traditional manufacturing process. 3D printing technology in the entire production process, from design to finished the whole process can be completed in the computer, and greatly improve production efficiency. Under these circumstances, 3D printing products can be made directly from the complexity of the target product without considering the complexity of the corresponding products. 3D printing technology in the entire process of production has a strong accuracy, accuracy mainly includes product size, shape and position accuracy[3].

\section{The application of three and 3D printing technology in die manufacturing}

In the past the traditional mould manufacturing in our country is mainly using some mapping software for analysis and correction, and then the feed point according to the characteristics of the products and to determine the dominant, the design of the parts and components for debugging and summary, the use of technology flow can be a waste of time, the whole technical process the first phase of production are laborious, very long, and in the production process of summary could not have any defects, otherwise it will cause greater losses. 3D printing technology at this stage can be transformed the traditional mold production method using reverse thinking, because of its shape and function of the structure and the precision has certain advantages, so it can effectively solve some of the problems in the production process, effectively reduce the design aspect of the traditional mold, resulting in products update said in a short time. The traditional mode of production in the mold industry can also be combined with 3D production technology in order to play its own advantages, and then the technology can also be better in its own mold production summary applications.

Generally speaking, the printing program of 3D printing technology in our country can be divided into the following three steps. First, the principle of 3D modeling. The effective use of 3D modeling software, the 3D model of product parameters were determined, then it will determine the model size and shape, quality of the final model can be printed by the later product quality target. Second, 3D print technology layered model. General printers have a certain automatic layered software, 3D modeling can be carried out at the work level of hierarchical processing, and each layer will have a certain product information. Under normal circumstances, if a product of its own layered more, then the quality of the product and accuracy will be higher, but also to a certain extent, reduce product productivity and printing efficiency. Third, 3D print stage. This refers to the reading stage of the printer, mainly through the powder and other basic materials through adhesive bonding, effective stacking layers of work, in order to form a good final product you want[4]. 


\section{D printing technology is limited at this stage reasons}

At present, 3D printing technology is very popular in our country. On the one hand, it can effectively save the raw materials used in the printing process, and on the other hand, it can also produce products with higher accuracy. The die has the characteristics of reducing manpower processing and so on. But also appeared some problems in the process of 3D printing technology, the development level is limited, the defects and mechanical properties of the mold, the size of the components will be limited, and print the materials needed is relatively small.

In the process of printing 3D technology, the mechanical properties of the printed mold can effectively affect the future use of the product. It is one of the important property parameters of the product component. Mechanical parameters are required to be used in material selection and design as well as analysis and manufacture of die components. The application of the general principle of the printer is NC machining method, this method can effectively ensure the mechanical properties of components, and in the process of printing products, heat treatment is effective to ensure components, time is too long, and the mechanical properties can be relatively good. 3D printing technology is effective if not die in the original heat treatment, can not guarantee the future components in the process of using the hardness and strength, these are to ask for the problem in 3D printing technology.

At this stage the use of print 3D printer specifications is limited, and some needed products can not print, can not meet the needs of the present stage, if you want to use the mold products in the future in industrial production, 3D printer technology at this stage is not able to complete the. Therefore, the effective development of ultra large mold technology and technical operation, production is necessary at this stage.

In general industrial manufacturing industry, many used kinds of mold, and mold for transmission and components there may exist certain difference, also because some parts of the different materials used are not the same. At this stage, we use in our country to use 3D printer technology materials are imported, mainly including imported materials and domestic materials, these materials also have certain characteristics of the mixed use. The parts needed for 3D printing materials may increase their cost due to limited material selection. Since 3D printers are a kind of printed software, the printers produced by different manufacturers have different R \& D software and, to some extent, also seriously affect the operation. At this stage, the 3D printer used in our country is only a simple stand-alone machine, and it is still unable to print remotely, and some online printing work. So some of the more advanced print jobs and services focus on the development of our 3D printing technology[5].

\section{D printing technology in the future development prospects}

The emergence of 3D printing technology to a certain extent, make up for the shortcomings of traditional printing technology, the mold processing technology can also meet the requirements of the product to a certain extent, has a unique advantage. However, there are still some shortcomings and shortcomings in 3D printing technology. The effective combination of traditional printing technology and mold and the current 3D printing technology is the development direction of the industry. Through certain efforts, effectively make all levels of excellence to the limit, to ensure that their respective strengths and circumvent weaknesses, and effectively improve their production efficiency. If an enterprise develops a new product, it can make use of the current 3D printing technology to produce and manage samples, so as to facilitate the revision and modification of the products in the future. After waiting for the product to meet the requirements in future use, the traditional method is used to transform the scale of technology. The traditional mode of production to make a tool, and then according to the corresponding sample products, such products should be carried out for the samples repeatedly, the final design to meet the requirements of the product. In the whole process of product design technology of 3D printing, because the procedure is complex, and there are some slow efficiency, drinking 3D technology effectively can be modified in the design of computer supervisor, simplify the production process of products. Effective large-scale 
production of products, because 3D printing technology is a stand-alone job, can not do mass production. But the use of traditional Abrasives manufacturing, production can be carried out in batches, and effectively speed up the production speed of products, further improve the production efficiency of products, thereby increasing the economic benefits of products. In addition, there is a need to further strengthen the relationship between traditional printing techniques and materials for producing products and eventually develop effective printing materials for use in future 3D printing technologies.

With the rapid development of 3D printing technology, the manufacturing industry, such as mold industry, is developing rapidly. The development between the two industries complements each other and promotes each other. In the future product manufacturing process, most of the products also need to use 3D printing technology to be able to produce, and need the mold to print. Also, 3D printing technology can effectively promote the mold industry update and improve, continue to solve the problem of 3D printing, 3D printing technology in the mold making process of research and development in the future have more broad application prospects[6].

\section{Conclusion}

As a result of the progress of society and the improvement of science and technology, 3D printing technology has gradually been widely used, and is a rapid prototyping technology in our country at this stage. Has received extensive attention and has been used in several fields. In addition, the mold manufacturing industry is the basis of our national industry, mold manufacturing industry has become an important industry in the national economy of our country, which plays an important role in the entire industry and manufacturing industry. 3D printing technology in the mold manufacturing industry in the application of the degree of deepening and expanding, has become a strong momentum in the future development of our country. 3D printing technology effectively complements the shortcomings of the traditional manufacturing methods, so that the mold manufacturing reform technology has made certain progress. This paper first analyzes the working principle and characteristics of 3D printing technology, and the use of 3D printing technology mold related to the analysis of the specific manufacturing, finally puts forward the existing problems of 3D printing technology and the development direction in the future, we hope to be able to 3D printing technology has certain help in mould manufacturing.

\section{References}

[1]Gao Q, Zeng H, Zhang D. Discussion on open experiment of rapid mould based on 3D printing technology[J]. Experimental Technology \& Management, 2016.

[2]Fengying H E. Brief Discussion on 3D Print Technology[J]. Mining Engineering, 2016.

[3]Ai J M, Du P. Discussion on 3D Print Model and Technology[J]. Applied Mechanics \& Materials, 2014, 543-547:130-133.

[4]Cao Y, Yao D. Research and Application of 3D Printing Technology in Water Cold Plate Manufacturing[J]. Aeronautical Manufacturing Technology, 2016.

[5]Dombroski C E, Balsdon M E, Froats A. The use of a low cost 3D scanning and printing tool in the manufacture of custom-made foot orthoses: a preliminary study[J]. Bmc Research Notes, 2014, 7(1):443.

[6]Genctav A, Genctav M, Tari S. DIFFUSION IS UBIQUITUS: A VOLUME DECOMPOSITION APPLICATION FOR 3D PRINTING[C]// Thermal and Fluids Engineering Summer Conference. 2016. 